\title{
Design, Qualification and Integration Testing of the High- Temperature Resistance Temperature Device for Stirling Power System
}

\author{
Jack Chan ${ }^{1}$, Dennis H. Hill ${ }^{2}$ \\ Lockheed Martin Space Systems Company, King of Prussia, Pennsylvania 19406 \\ Remo Elisii ${ }^{3}$, Jonathan R. White ${ }^{4}$ \\ Lockheed Martin Space Systems Company, King of Prussia, Pennsylvania 19406 \\ Edward J. Lewandowski ${ }^{5}$ \\ NASA Glenn Research Center, Cleveland, OH 44135 \\ and \\ Salvatore M. Oriti ${ }^{6}$ \\ NASA Glenn Research Center, Cleveland, $\mathrm{OH} 44135$
}

\begin{abstract}
The Advanced Stirling Radioisotope Generator (ASRG), developed from 2006 to 2013 under the joint sponsorship of the United States Department of Energy (DOE) and National Aeronautics and Space Administration (NASA) to provide a high-efficiency power system for future deep space missions, employed Sunpower Incorporated's Advanced Stirling Convertors (ASCs) with operating temperature up to $840{ }^{\circ} \mathrm{C}$. High-temperature operation was made possible by advanced heater head materials developed to increase reliability and thermal-to-mechanical conversion efficiency. During a mission, it is desirable to monitor the Stirling hot-end temperature as a measure of convertor health status and assist in making appropriate operating parameter adjustments to maintain the desired hotend temperature as the radioisotope fuel decays. To facilitate these operations, a Resistance Temperature Device (RTD) that is capable of high-temperature, continuous long-life service was designed, developed and qualified for use in the ASRG. A thermal bridge was also implemented to reduce the RTD temperature exposure while still allowing an accurate projection of the ASC hot-end temperature. NASA integrated two flight-design RTDs on the ASCs and assembled into the highfidelity Engineering Unit, the ASRG EU2, at Glenn Research Center (GRC) for extended operation and system characterization. This paper presents the design implementation and qualification of the RTD, and its performance characteristics and calibration in the ASRG EU2 testing.
\end{abstract}

\section{Introduction}

$\mathrm{T}$ he Advanced Stirling Radioisotope Generator (ASRG) was under development from 2006 to 2013 with the objective of providing a high-efficiency, low-mass radioisotope power system for future National Aeronautics and Space Administration (NASA) missions. The ASRG offers the advantage of a four-fold increase in thermal-toelectrical conversion efficiency compared to the current thermoelectric conversion technology. With the reduced radioisotope fuel consumption per unit power output, the use of ASRG could extend the limited domestic plutonium supply and provide more mission opportunities that require radioisotope power systems. The high efficiency and

\footnotetext{
${ }^{1}$ Principal Systems Engineer, 230 Mall Boulevard, B100/M2307.

${ }^{2}$ Senior Staff Mechanical Engineer, 230 Mall Boulevard, B100/M2407.

${ }^{3}$ Staff Mechanical Engineer, 230 Mall Boulevard, B100/M2407.

${ }^{4}$ Senior Staff Aeronautical Engineer, 230 Mall Boulevard, B100/M4610.

${ }^{5}$ Project Lead Engineer, Thermal Energy Conversion Branch, 21000 Brookpark Rd.

${ }^{6}$ Mechanical Engineer, Thermal Energy Conversion Branch, 21000 Brookpark Rd.
} 
low-temperature waste heat rejection of the ASRG also facilitates more options in integrating the power systems to the spacecraft. For the ASRG flight development project, Lockheed Martin Space Systems Company served as the system integrator under contract to the Department of Energy (DOE). Sunpower's free-piston Advanced Stirling Convertor (ASC) used in the ASRG was designed and developed initially under a NASA Research Announcement contract; the qualification and flight ASCs were designed and developed on a DOE prime contract to Lockheed Martin with a directed subcontract to Sunpower in the ASRG project ${ }^{1}$.

The ASRG Engineering Unit ${ }^{2}$ (EU) built and tested in 2008 incorporated first-generation ASCs (ASC-Es) that employed Inconel (In-718) as the heater head material. This limited the hot-end temperature to $650{ }^{\circ} \mathrm{C}^{3}$ when creep becomes a reliability consideration for long-life operation. Given that the hot-end temperature affects both power conversion efficiency and ASC reliability, continuous monitoring of the ASC operating temperature was desired. For ASRG EU, this temperature sensing was accomplished via the platinum resistance temperature devices (RTDs) mounted directly to the heat collector of each ASC. Hot-end temperature was one of three ASC control options (temperature, piston amplitude, and alternator voltage) the electronic controller can utilize to adjust the ASC operating conditions in the ASRG EU. A vendor supplied the RTD that was designed and qualified for satellite propulsion subsystem application, which requires intermittent use as compared to continuous high-temperature exposure as in the ASRG. During ASRG EU testing, the RTDs were found to drift with increased resistance. Upon investigation, evidence of cracks/breaks in the platinum element was found on separate RTDs from the same batch following exposure to continuous high temperature. Since a different implementation was planned for the flight ASRG, no further failure analysis or root cause investigation was performed for the EU RTDs.

The flight ASC, as illustrated in Fig. 1, was designed to increase the operating temperature to $840{ }^{\circ} \mathrm{C}$ with the use of nickel superalloy 247 LC $^{1}$, instead of In-718, as the heater head material originally intended for the ASC (In-

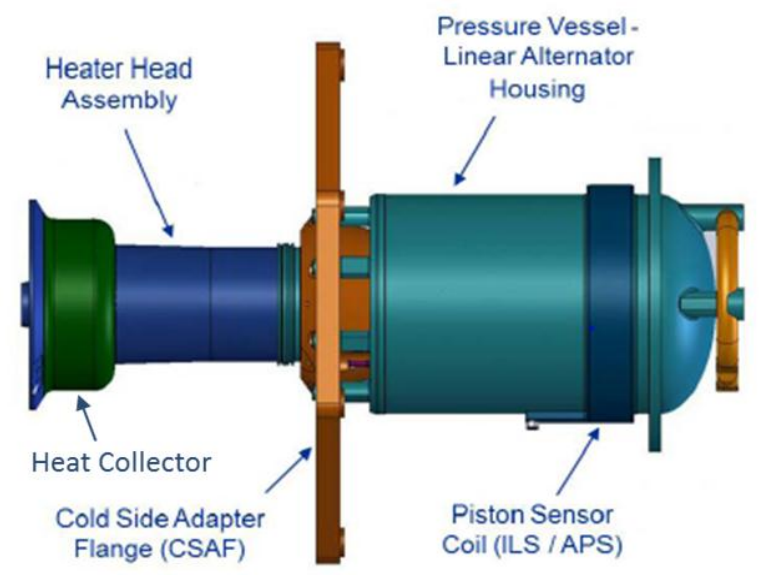

Figure 1. Flight ASC Configuration. 718 was used in the ASRG EU only as a developmental bridge prior to the completion of ASC design). This higher temperature posed a challenge in implementing a sensor that can operate reliably and continuously for a 17 year mission. As part of ASRG flight design modifications from the EU, the ASCs are controlled only via open-loop voltage control rather than in the closedloop constant temperature or constant piston amplitude modes described above. This mitigates the stringent requirements placed on the reliability of both the temperature and piston sensors, which were now used for health status telemetry and periodic adjustments of hotend temperature.

To accommodate the $840{ }^{\circ} \mathrm{C}$ operating temperature for the flight ASC, a custom RTD was designed by Rosemount Aerospace Inc. with several engineering prototypes tested to demonstrate its performance characteristics. With the final design confirmed, a set of qualification RTDs were fabricated and underwent a comprehensive test program to qualify the design for flight use in the ASRG. An innovative approach to integrate the RTD to the ASC was developed to reduce its temperature exposure. RTDs with the same flight design were procured by NASA Glenn Research Center (GRC) and integrated on the ASCs in the EU2 that were put into extended operation and performance characterization.

\section{RTD Design and Integration}

The RTD has been used extensively, though only in low temperature application around $250{ }^{\circ} \mathrm{C}$, in the General Purpose Heat Source-Radioisotope Thermoelectric Generator (GPHS-RTG) as well as the Multi-Hundred Watt (MHW) generators. Thus the long-term operation of RTD in vacuum environment has been fully demonstrated in missions such as Cassini, which continues to transmit temperature data after 17 years in space.

For continuous high-temperature sensing and long-life operation, it was recommended that the RTD be exposed to less than $600{ }^{\circ} \mathrm{C}$ to prevent contamination of the resistive element with minute impurities from the interior components and metal sheath of the device. Working with Rosemount Aerospace, the same vendor that supplied the RTDs for the GHPS-RTGs, a Source Control Drawing (SCD) was developed that established the performance, design, fabrication, qualification test and acceptance test requirements for the RTD. Platinum material in wirewound element configuration was selected for the design. A four-wire sensor resistance measurement configuration 
was also specified to provide the most accurate resistance measurement. In a four wire measurement, two wires are used to flow current and the other two wires are used to sense voltage, thereby minimizing the measurement error due to lead resistance. The RTDs were hermetically sealed to allow for extensive ground testing and operation prior to space flight mission.

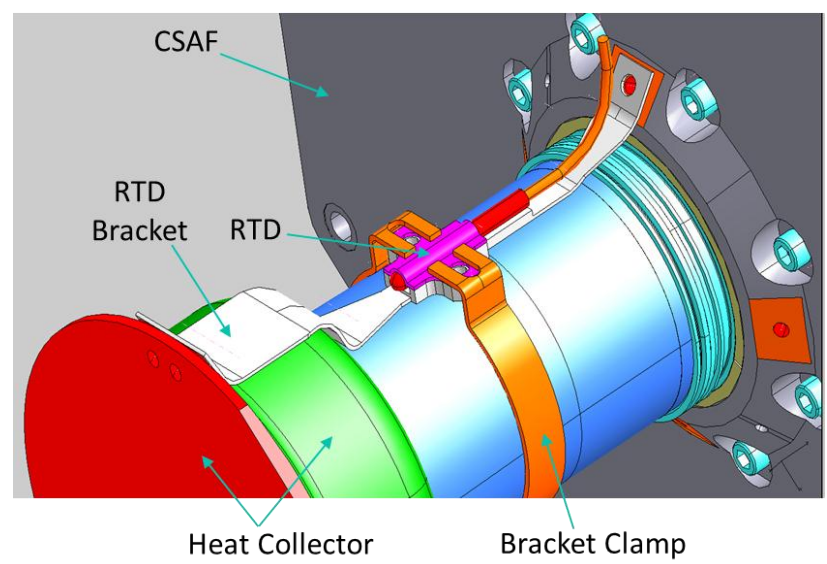

Figure 2. RTD and Bracket Attachment on ASC.
To reduce the high-temperature exposure, the RTD was moved to a cooler location on the ASC. A bracket was designed as shown in Fig. 2 to span the distance between the heat collector (attached to the acceptor) and the Cold-Side Adaptor Flange (CSAF) (attached to the rejector) with a temperature gradient in the bracket matching that of the heater head assembly. This matching of temperature gradient profiles minimizes thermal coupling between the heater head assembly and the bracket. To minimize thermal loss from the heater head assembly wall to the surroundings, the heater head assembly was also wrapped with quartz yarn. The RTD was placed at the point along the bracket where the temperature was predicted to be 600 ${ }^{\circ} \mathrm{C}$ or less under all possible operating conditions during ground testing and mission operation. Since the bracket was also attached to the rejector, the RTD temperature was dependent on both the acceptor and rejector temperatures. A thermistor located on the CSAF was used in conjunction with the RTD to extrapolate the acceptor temperature. The thermistor located on the CSAF measures a temperature that is about $2{ }^{\circ} \mathrm{C}$ lower than the rejector temperature.

Thermal analysis was performed to size the bracket configuration to closely match the temperature gradient of the heater head assembly and to minimize the conduction loss from the heat collector to the CSAF. The analysis included bracket material options and bracket configurations with different thicknesses and widths along the axial length. A material trade study was performed to compare RTD brackets using Haynes 230, titanium alloy (Ti6Al4V) and 247 LC. Conductive heat losses due to the RTD bracket for a nominal mission operating condition are $0.64,0.74$ and $0.91 \mathrm{~W}$ for titanium, $247 \mathrm{LC}$, and Haynes 230, respectively. The material trade study resulted in the selection of 247 LC for the RTD bracket because a good match to the thermal gradient to the 247 LC heater head assembly was obtained with bracket sizing that could be manufactured and possible thermal distortion and material interaction concerns if other materials are used.

To size the RTD bracket width and thickness, the ASRG thermal model was used with detailed attention paid to the ASC heater head assembly wall thickness as it varies along the length. The goal was to maintain a similar variation in cross sectional area compared to the heater head such that the temperature gradient profiles are as closely matched as possible. Figure 3 shows the thermal model for the RTD bracket and the typical temperature profiles along the length for two ASC acceptor and rejector temperature combinations. The final bracket design has a constant thickness with segments of different width along the length. The bracket conduction loss is between 0.40 and $0.60 \mathrm{~W}$, depending on the operating temperature conditions of the ASC acceptor and rejector.
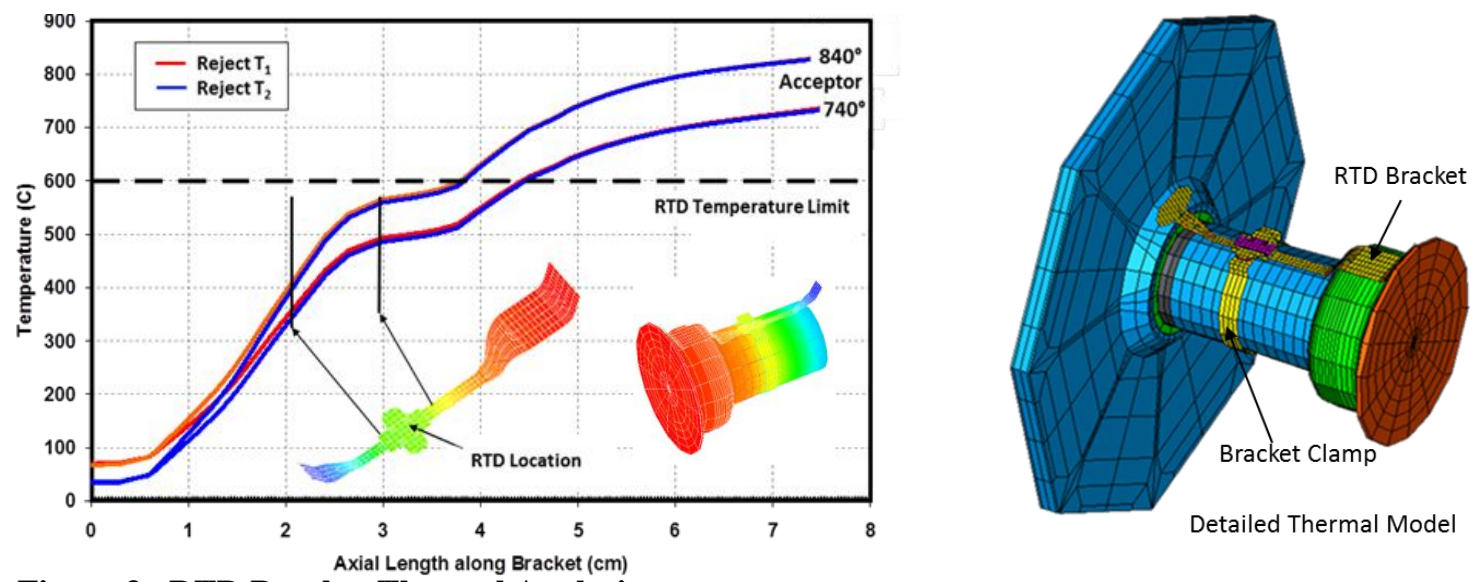

Figure 3. RTD Bracket Thermal Analysis.

American Institute of Aeronautics and Astronautics 
A generator model simulation was used to predict RTD temperature as a function of ASC acceptor and rejector temperatures as shown in Table 1 for several operating conditions. The relationship between the RTD sensed temperature and the acceptor / rejector temperatures is governed by thermal conduction and is therefore linear. A linear relationship for acceptor temperature as a function of the RTD and rejector temperatures can be expressed in the form of $\mathrm{T}_{\text {acceptor }}=\mathrm{a}+\mathrm{b}_{1} * \mathrm{~T}_{\mathrm{RTD}}+\mathrm{b}_{2} * \mathrm{~T}_{\text {rejector, }}$, where $\mathrm{a}=87.02, \mathrm{~b} 1=1.35$ and $\mathrm{b} 2=-0.19$ for the simulation values shown in Table 1. The errors compared to the simulated acceptor temperature are in the range from -0.44 to $0.91^{\circ} \mathrm{C}$.

Table 1. Examples of RTD Temperature Simulation Results.

\begin{tabular}{|c|c|c|}
\hline $\begin{array}{c}\text { Acceptor } \\
\text { Temp., }\end{array}{ }^{\circ} \mathbf{C}$ & $\begin{array}{c}\text { Rejector } \\
\text { Temp., }^{\circ} \mathrm{C}\end{array}$ & $\begin{array}{c}\text { Max. RTD } \\
\text { Temp., }^{\circ} \mathbf{C}\end{array}$ \\
\hline 740 & 100 & 498 \\
\hline 790 & 100 & 534 \\
\hline 840 & 100 & 571 \\
\hline 740 & 50 & 490 \\
\hline 790 & 50 & 527 \\
\hline 840 & 50 & 565 \\
\hline
\end{tabular}

This is well within the accuracy needed to ensure safe operation of the ASC and for power output control during mission. Any error associated with the RTD measurements will be magnified when using the linear equation above to project the acceptor temperature. However, since platinum RTDs can attain accuracies on the order of $\pm 0.1^{\circ} \mathrm{C}$ and the RTD will be calibrated during ground test, the actual error will be negligible. Long-term RTD drift, on the other hand, can be magnified by a factor of 1.35 based upon the coefficient b1 shown in the sample equation above.

\section{RTD Qualification}

With the critical design review of the RTD completed in 2010, 16 RTDs were produced by Rosemount Aerospace for qualification testing in three groups: standard testing, life testing and radiation test. The test matrix is shown in Table 2 and a photograph of the qualification RTD is shown in Fig. 4. Tests conducted at Rosemount Aerospace were in accordance with the requirements defined in the Lockheed Martin SCD with test methods per MIL-PRF23648 and MIL-STD-202. All 16 RTDs were subjected to random vibration test at the operating temperature of 600 $+60 /-15{ }^{\circ} \mathrm{C}$ and at the dynamic level that will be experienced by the units when installed in the qualification ASRG and tested as a system. The RTD random vibration test was set up with an acetylene torch positioned to heat the RTD sensor to operating temperature. Similarly, the mechanical shock test was also performed at temperature on two of the units. All units tested at Rosemount Aerospace passed the acceptance criteria.

Table 2. RTD Qualification Test Matrix.

\begin{tabular}{|l|c|c|c|}
\hline \multicolumn{1}{|c|}{ Test Description } & $\begin{array}{c}\text { Standard } \\
\text { Testing }\end{array}$ & $\begin{array}{c}\text { Life } \\
\text { Testing }\end{array}$ & $\begin{array}{c}\text { Radiation } \\
\text { Testing }\end{array}$ \\
\hline No. of Unit & 2 & 9 & 3 \\
\hline Hermetic Sealing & $\mathrm{X}$ & $\mathrm{X}$ & $\mathrm{X}$ \\
\hline High-Temp. Burn-in \& IR & $\mathrm{X}$ & $\mathrm{X}$ & $\mathrm{X}$ \\
\hline High-Temp. Soak & $\mathrm{X}$ & & \\
\hline Calibration & $\mathrm{X}$ & $\mathrm{X}$ & $\mathrm{X}$ \\
\hline Insulation Resistance & $\mathrm{X}$ & $\mathrm{X}$ & $\mathrm{X}$ \\
\hline Random Vibration & $\mathrm{X}$ & $\mathrm{X}$ & $\mathrm{X}$ \\
\hline Mechanical Shock & $\mathrm{X}$ & & \\
\hline Short Time Overload & $\mathrm{X}$ & & \\
\hline Dissipation Constant & $\mathrm{X}$ & $\mathrm{X}$ & $\mathrm{X}$ \\
\hline Response Time & $\mathrm{X}$ & $\mathrm{X}$ & $\mathrm{X}$ \\
\hline Reliability Life & & $\mathrm{X}$ & \\
\hline Radiation & & & $\mathrm{X}$ \\
\hline
\end{tabular}

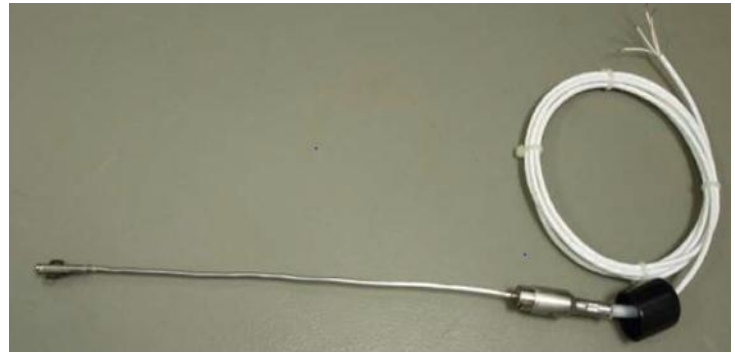

Figure 4. Qualification RTD.

The life and reliability requirements were verified by testing nine RTDs at temperature in vacuum for 12 months at Lockheed Martin with intermittent hermetic sealing and calibration tests performed at four-month intervals at Rosemount Aerospace. The RTD drift at $600{ }^{\circ} \mathrm{C}$ was then determined based on the resistance drift calculated at the ice-point (Ro at $0{ }^{\circ} \mathrm{C}$ ). Ro was used as the baseline for the drift calculation because of the larger calibration uncertainty at $600{ }^{\circ} \mathrm{C}$. Figure 5 shows the resulting temperature drifts for the 9 RTDs through the 12-month test duration, with unit serial number AA008 exhibiting the largest drift. One unit was discontinued after eight months of test due to a part fracture from handling. The fitted curves for the average and the upper bound drifts are shown in the figure using a Weibull function and a 3-sigma value from the scattered data. Using the fitted curves, the average and upper bound drifts were predicted at $1.13{ }^{\circ} \mathrm{C}$ and $2.54{ }^{\circ} \mathrm{C}$, respectively, over an eight-year period, well within the drift limit specified during the RTD operating life. 


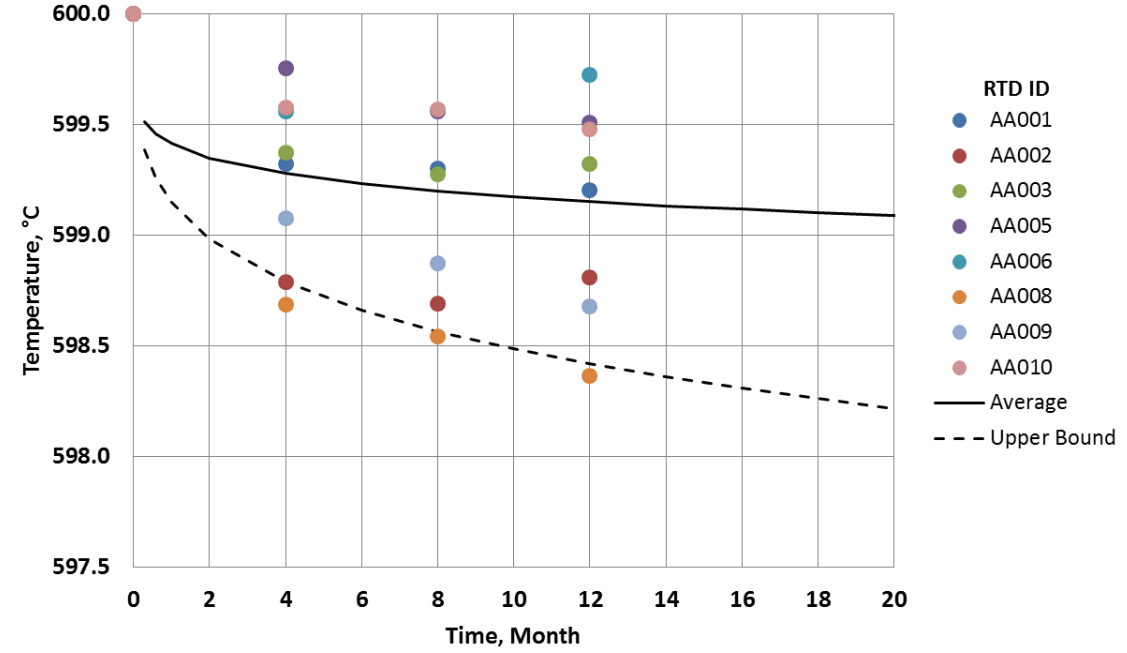

Figure 5. RTD One-Year Temperature Drifts.
Since the RTD is located close to the GPHS in the ASRG, it is subjected to gamma and neutron radiation exposures that are significantly higher than from typical space environment. As a part of qualification, three RTDs were subjected to radiation test as identified in Table 2. Three neutron irradiations with a total dose of 2.4E13 n/ $/ \mathrm{cm}^{2}$ were conducted followed by a gamma dose at $400 \mathrm{krad}(\mathrm{Si})$, all at room temperature. Between each test, insulation resistance to case at room temperature and resistance at $-10,100$ and $185{ }^{\circ} \mathrm{C}$ were measured. No significant shifts

in resistance measurements were seen during any of the testing increments. The RTD qualification was successfully completed in September 2013 and the design was ready for flight production.

\section{RTD Integration and System-Level Test}

With the termination of flight ASRG project at end of 2013, NASA is continuing the testing of flight-like ASRG hardware to support the potential development of future Stirling-based power systems ${ }^{3}$. An engineering generator, the ASRG EU2, was built and put into system-level testing at NASA GRC. To closely match the design and functionalities of the flight ASRG, the RTDs were procured from Rosemount Aerospace by GRC to the ASRG flight design. An RTD was installed in each ASC in the flight configuration as shown in Fig. 6. The ASC heat collector was instrumented with two thermocouples and the CSAF was instrumented with a thermistor near the rejector to be used for RTD calibration to derive a linear equation as discussed in Section II. For the flight ASRG,

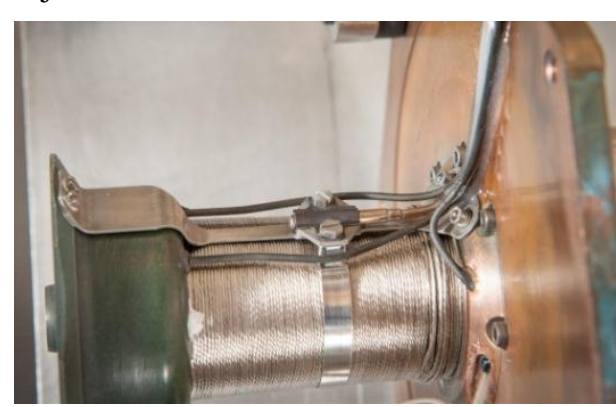

Figure 6. RTD Installation on the ASC.

\begin{abstract}
the heat collector thermocouples will provide the temperature data during the initial testing in the electricallyheated configuration and will be disconnected for flight when the ASRG is opened for GPHS fueling. This leaves the RTD as the only ASC acceptor temperature sensor during the mission.
\end{abstract}

The EU2 generator, shown in Fig. 7, operates in air with internal volume filled with argon cover gas or under vacuum. With the external environment limited to ambient room air condition, active cooling loops attached to the housing are used to remove the ASC waste heat from the rejector at various temperatures to simulate the operating conditions during a mission. With this test configuration, the ASC acceptor and rejector temperatures can be varied to obtain RTD resistance measurements for temperature calibration.

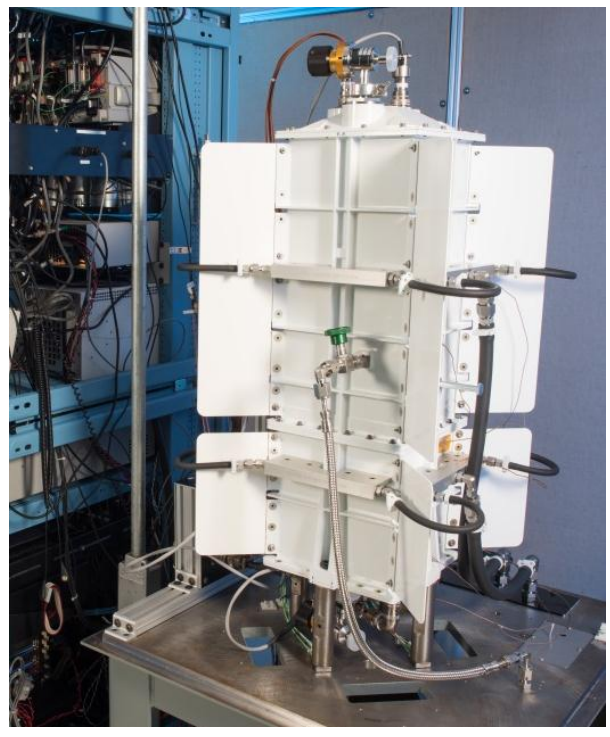

Figure 7. EU2 Test Setup.

\section{RTD Test Data and Calibration}

The ASRG EU2 generator started 24/7 continuous operation in August 2014 with argon cover gas inside the generator housing. The ASCs were initially operated under the control of an AC bus. The ASC control was then 
switched to an Engineering Development Unit (EDU) controller ${ }^{4}$ that was designed during the ASRG project and fabricated and delivered to GRC under a NASA contract. Test data for each ASC acceptor, CSAF, and RTD operating in the typical temperature region during a space flight mission is shown in Fig. 8.

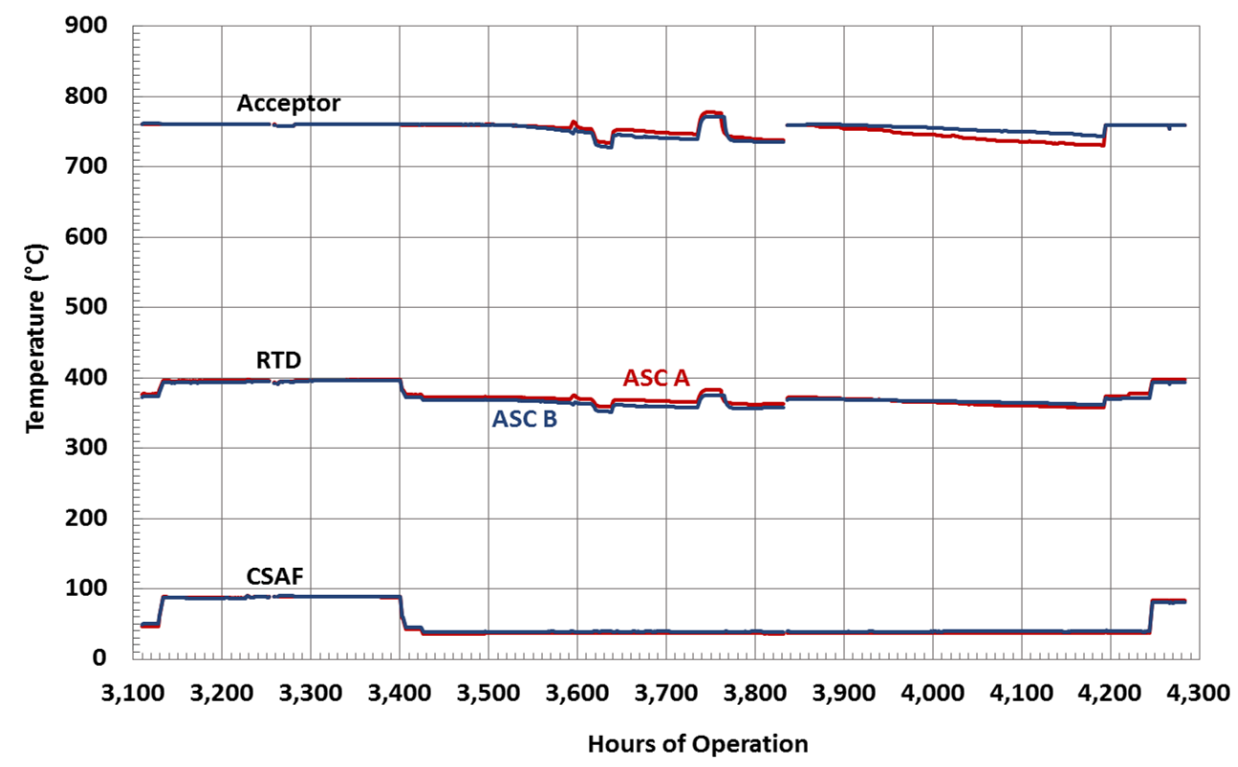

Figure 8. EU2 ASC Operating Temperature Profiles.

As discussed in Section II, the relationship among the RTD, acceptor, and rejector temperatures is linear via the conduction of the RTD bracket from hot to cold end. The EU2 test data for the RTD and bracket assembly indicates acceptable agreement with the analytical prediction shown in Section II. The length of the RTD platinum coil is approximately $2.54 \mathrm{~cm}$ and its mid-point, which corresponds to the measured coil resistance and temperature reading, is located near the cold end of the RTD mount on the bracket shown in Figs. 3 and 6. Fifteen steady-state data points were selected from Fig. 8 and are grouped in three RTD / CSAF temperature ranges, as shown in Table 3. Group A covers the higher CSAF temperature conditions, Group B covers the intermediate RTD temperatures, and Group C covers the lower RTD temperatures. Grouping the test data into narrower temperature bands should result in correlations that allow for more accurate predictions of the acceptor temperatures from the RTD and CSAF thermistor readings.

Table 3. ASC Measured and Predicted Temperatures in ${ }^{\circ} \mathrm{C}$.

\begin{tabular}{|c|c|c|c|c|c|c|c|c|c|c|c|}
\hline \multirow{3}{*}{ Group } & \multirow{3}{*}{$\begin{array}{c}\text { Hour of } \\
\text { Operation }\end{array}$} & \multicolumn{5}{|c|}{ ASC-A } & \multicolumn{5}{|c|}{ ASC-B } \\
\hline & & \multicolumn{3}{|c|}{ Measurement } & \multicolumn{2}{|c|}{ Prediction } & \multicolumn{3}{|c|}{ Measurement } & \multicolumn{2}{|c|}{ Prediction } \\
\hline & & Acceptor & RTD & CSAF & Acceptor & Error & Acceptor & RTD & CSAF & Acceptor & Error \\
\hline \multirow{4}{*}{ A } & 3,129 & 760.4 & 382.4 & 59.8 & 760.4 & 0.0 & 761.7 & 379.6 & 61.4 & 761.6 & -0.1 \\
\hline & 3,246 & 760.9 & 396.5 & 88.8 & 761.2 & 0.3 & 760.9 & 395.0 & 88.5 & 761.1 & 0.3 \\
\hline & 3,399 & 761.2 & 397.2 & 88.2 & 760.8 & -0.4 & 760.7 & 396.6 & 88.3 & 760.3 & -0.4 \\
\hline & 4,281 & 759.6 & 397.4 & 83.2 & 759.7 & 0.1 & 759.4 & 393.8 & 80.4 & 759.6 & 0.2 \\
\hline \multirow{6}{*}{ B } & 3,126 & 760.2 & 377.1 & 46.9 & 759.6 & -0.6 & 761.8 & 373.8 & 50.1 & 760.9 & -0.9 \\
\hline & 3,423 & 759.9 & 375.8 & 42.3 & 760.8 & 0.9 & 760.2 & 372.5 & 45.4 & 761.7 & 1.5 \\
\hline & 3,480 & 759.7 & 371.8 & 35.8 & 758.8 & -0.9 & 760.1 & 368.4 & 38.0 & 759.4 & -0.7 \\
\hline & 3,760 & 776.6 & 382.4 & 37.1 & 776.4 & -0.2 & 771.5 & 375.6 & 38.8 & 771.3 & -0.2 \\
\hline & 3,871 & 758.0 & 371.6 & 36.6 & 757.9 & -0.1 & 761.2 & 369.9 & 38.9 & 761.5 & 0.4 \\
\hline & 4,217 & 759.7 & 373.5 & 37.4 & 760.5 & 0.8 & 759.8 & 370.4 & 39.4 & 762.0 & 2.2 \\
\hline \multirow{5}{*}{ C } & 3,733 & 746.6 & 365.7 & 37.2 & 747.2 & 0.6 & 739.2 & 357.7 & 38.9 & 737.5 & -1.6 \\
\hline & 3,830 & 738.1 & 362.7 & 35.9 & 738.5 & 0.4 & 735.7 & 357.3 & 38.0 & 736.6 & 0.8 \\
\hline & 3,981 & 746.4 & 365.5 & 36.6 & 745.6 & -0.8 & 756.6 & 367.7 & 39.0 & 756.0 & -0.6 \\
\hline & 4,081 & 737.0 & 360.7 & 37.0 & 736.8 & -0.1 & 750.9 & 365.0 & 39.4 & 751.2 & 0.4 \\
\hline & 4,191 & 730.6 & 357.3 & 37.2 & 730.5 & 0.0 & 743.4 & 361.3 & 39.6 & 744.4 & 1.0 \\
\hline
\end{tabular}

6

American Institute of Aeronautics and Astronautics 
Using the Microsoft Excel linear regression function, the predicted acceptor temperatures for the 15 data points are shown in Table 3 along with the associated errors. The coefficients for the linear equations used to predict the acceptor temperatures are shown in Table 4 . The errors in the prediction are well within the accuracy required to provide the trending telemetry needed for health monitoring and operational adjustments of the ASCs when required during a mission.

Table 4. Coefficients for the Predicted ASC Acceptor Temperatures in Table 2.

\begin{tabular}{|c|rrr|rrr|}
\hline \multirow{2}{*}{ Group } & \multicolumn{3}{|c|}{ ASC-A } & \multicolumn{3}{c|}{ ASC-B } \\
\cline { 2 - 7 } & \multicolumn{1}{|c|}{ a } & b1 & b2 & \multicolumn{1}{c|}{ a } & b1 & b2 \\
\hline \hline A & 893.2 & -0.380 & 0.210 & 940.6 & -0.516 & 0.276 \\
B & 131.5 & 1.762 & -0.776 & 152.4 & 1.716 & -0.655 \\
C & -53.0 & 1.984 & 2.009 & 61.5 & 1.861 & 0.264 \\
\hline \multicolumn{4}{|c|}{ Predicted $\mathbf{T}_{\text {acceptor }}=\mathbf{a}+\mathbf{b 1} * \mathbf{T}_{\mathrm{RTD}}+\mathbf{b 2} * \mathbf{T}_{\text {CSAF }}$} \\
\hline
\end{tabular}

The nominal range of the acceptor temperature during a typical space mission is expected to be between 740 and $780{ }^{\circ} \mathrm{C}$, which has at least a $60{ }^{\circ} \mathrm{C}$ margin to the maximum allowable temperature of $840{ }^{\circ} \mathrm{C}$. This limits the RTD temperature exposure to below $600{ }^{\circ} \mathrm{C}$ as shown in Fig. 3 .

It is planned that a complete RTD temperature calibration test will be performed with the ASRG EU2 covering a wide range of ASC acceptor and rejector temperature with the housing in both argon and vacuum conditions. These data will allow for further calibration of the RTDs and simulate the process which a flight ASRG will go through to obtain the database for missions.

\section{Conclusion}

The RTD design, development and qualification have been successfully completed for its use in flight applications that require continuous measurements of high-temperature components during their mission life, as in the case of the ASRG Stirling convertors. The engineering RTD of the same flight design was built and assembled into the ASRG EU2 at NASA GRC. EU2 test data to date show that the RTDs perform as expected with results in close agreement with the analysis. The RTD correlation can predict the acceptor temperature with acceptable accuracy. The implementation approach of the RTD in the ASRG limits its temperature exposure to below the industrial standard for platinum sensor and allows for monitoring of much higher temperature operation. Further RTD calibration testing is planned in the EU2 to characterize the range of performance and demonstrate its longterm, reliable operation.

\section{Acknowledgments}

This work is funded through the NASA Science Mission Directorate. The RTD design and qualification efforts were managed by DOE. The system-level integration and EU2 testing with RTDs is managed by the NASA Radioisotope Power System Program Office. Any opinions, findings, conclusions or recommendations expressed in this article are those of the authors and do not necessarily reflect the views of DOE or NASA.

\section{References}

${ }^{1}$ Wong, W.A., Wilson, S., and Collins, J., "Advanced Stirling Convertor (ASC) Development for NASA RPS", Proceedings of the 12 ${ }^{\text {th }}$ International Energy Conversion Engineering Conference (IECEC), AIAA-2014-3962, Cleveland, OH, 2014.

${ }^{2}$ Chan, J., Hill, H., Hoye, T., and Leland, D., "Development of Advanced Stirling Radioisotope Generator For Planetary Surface and Deep Space Missions," Proceedings of the $6^{\text {th }}$ International Energy Conversion Engineering Conference and Exhibit (IECEC), AIAA-2008-5656, Cleveland, OH, 2008.

${ }^{3}$ Lewandowski, E.J., Bolotin, G.S., and Oriti, S.M., "Test Program for Stirling Radioisotope Generator Hardware at NASA Glenn Research Center," Proceedings of the $12^{\text {th }}$ International Energy Conversion Engineering Conference (IECEC), AIAA2014-3964, Cleveland, OH, 2014.

${ }^{4}$ Chan, J., Wiser, J., Brown, G., Florin, D., and Oriti, S.M., "System-Level Testing of the Advanced Stirling Radioisotope Generator Engineering Hardware," Proceedings of the 12 ${ }^{\text {th }}$ International Energy Conversion Engineering Conference (IECEC), AIAA-2014-3966, Cleveland, OH, 2014. 